\title{
Interactive visualization of brain-scale spiking activity
}

\author{
Christian Nowke ${ }^{1,5^{*}}$, Bernd Hentschel ${ }^{1,5}$, Torsten Kuhlen ${ }^{1,5}$, Maximilian Schmidt ${ }^{2,5}$, Sacha J van Albada ${ }^{2,5}$, \\ Jochen M Eppler ${ }^{2,5}$, Rembrandt Bakker ${ }^{2,3,5}$, Markus Diesmann $2,4,5$ \\ From Twenty Second Annual Computational Neuroscience Meeting: CNS*2013 \\ Paris, France. 13-18 July 2013
}

In recent years, the simulation of spiking neural networks has advanced in terms of both simulation technology $[1,2]$ and knowledge about neuroanatomy [3,4]. Due to these advances, it is now possible to run simulations at the brain scale $[5,6]$, which produce an unprecedented amount of data to be analyzed and understood by researchers.

To aid computational neuroscientists with the development of models and especially with the visual inspection and selection of data for analysis, we developed VisNEST
[7], a tool for the combined visualization of simulated spike data and anatomy. This provides a rapid overview of the relationship between structure and activity. VisNEST currently uses spike data from the neural simulation tool NEST [1] and geometry from the Scalable Brain Atlas [4], but is not limited to these tools.

In our contribution we will present VisNEST using a Picasso 3D system, which allows users to interactively investigate and explore the simulated data from a large-scale

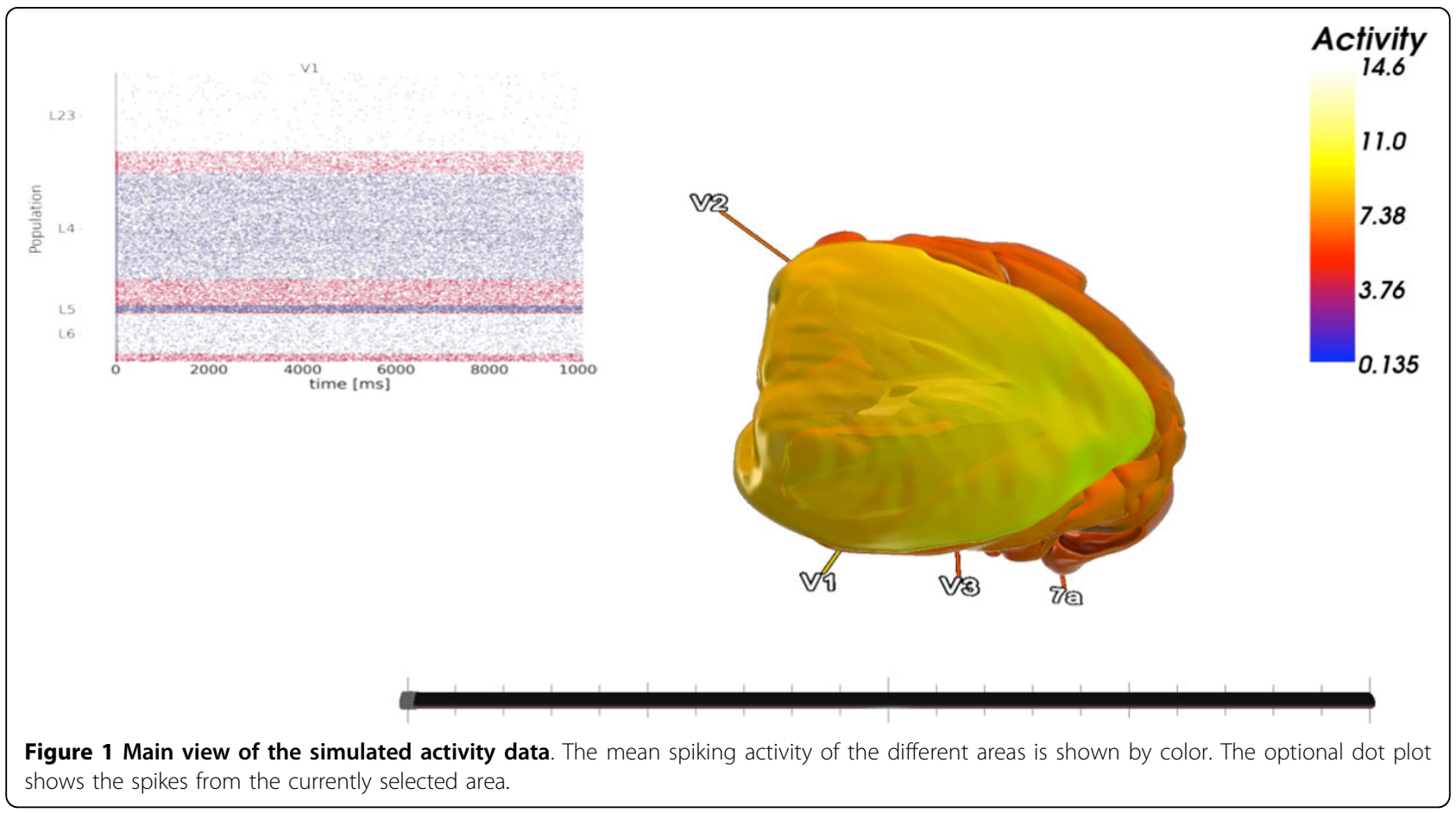

* Correspondence: nowke@vr.rwth-aachen.de

'Virtual Reality Group, RWTH Aachen University, Aachen, Germany

Full list of author information is available at the end of the article 
model of 32 vision-related areas of the macaque [6]. The system is equipped with infrared tracking and uses passive glasses to render the image for the user standing in front of the screen.

\section{Acknowledgements}

Partially supported by the Helmholtz Association: HASB and portfolio theme SMHB, the Next-Generation Supercomputer Project of MEXT, EU Grant 269921 (BrainScaleS), by the VSR computation time grant JINB33 on the JUGENE and JUQUEEN supercomputers in Jülich, the Jülich-Aachen Research Alliance (JARA) and by the Excellence Initiative of the German federal and state governments.

\section{Author details}

'Virtual Reality Group, RWTH Aachen University, Aachen, Germany. ${ }^{2}$ Institute of Neuroscience and Medicine (INM-6) and Institute for Advanced Simulation (IAS-6), Jülich Research Centre, Jülich, Germany. ${ }^{3}$ Donders Institute for Brain, Cognition and Behavior, Radboud University, Nijmegen, The Netherlands. ${ }^{4}$ Medical Faculty, RWTH Aachen University, Aachen, Germany. ${ }^{5}$ JARA - HighPerformance Computing, RWTH Aachen University, Aachen, Germany.

Published: 8 July 2013

\section{References}

1. Gewaltig MO, Diesmann M: NEST (NEural Simulation Tool). Scholarpedia 2007, 2(4):1430.

2. Helias M, Kunkel S, Masumoto G, Igarashi J, Eppler JE, Ishii S, Fukai T, Morrison A, Diesmann M: Supercomputers ready for use as discovery machines for neuroscience. Front Neuroinform 2012, 6:26.

3. Stephan KE, Kamper L, Bozkurt A, Burns GAPC, Young MP, Kötter R: Advanced database methodology for the collation of connectivity data on the macaque brain (CoCoMac). Phil Trans R Soc Lond B 2001, 356

4. Bakker R, Bezgin G: Scalable brain atlas. 2012 [http://scalablebrainatlas.incf. org/].

5. Potjans T, Diesmann M: The cell-type specific cortical microcircuit: relating structure and activity in a full-scale spiking network model. Cerebral Cortex 2012, doi:10.1093/cercor/bhs358.

6. Schmidt M, van Albada S, Bakker R, Diesmann M: Toward a spiking multiarea network model of macaque visual cortex. Tenth Göttingen Meeting of the German Neuroscience Society 2013.

7. Nowke C, Hentschel B, Kuhlen T, Eppler JM, van Albada S, Bakker R, Diesmann M, Schmidt M: VisNest - Interactive Analysis of Neural Activity Data. IEEE VIS 2012 Poster Abstracts 2012.

doi:10.1186/1471-2202-14-S1-P110

Cite this article as: Nowke et al:: Interactive visualization of brain-scale spiking activity. BMC Neuroscience 2013 14(Suppl 1):P110.

\section{Submit your next manuscript to BioMed Central and take full advantage of:}

- Convenient online submission

- Thorough peer review

- No space constraints or color figure charges

- Immediate publication on acceptance

- Inclusion in PubMed, CAS, Scopus and Google Scholar

- Research which is freely available for redistribution

Submit your manuscript at www.biomedcentral.com/submit
C Biomed Central 